\title{
An Azobenzene-Based Single-Component Supramolecular Polymer Responsive to Multiple Stimuli in Water
}

\author{
Edgar Fuentes, Marieke Gerth, José Augusto Berrocal, Carlo Matera, Pau Gorostiza, Ilja K. Voets, \\ Silvia Pujals, * and Lorenzo Albertazzi*
}

Cite This: J. Am. Chem. Soc. 2020, 142, 10069-10078

Read Online

\section{ACCESS | Llll Metrics \& More | 回 Article Recommendations | (s) Supporting Information}

ABSTRACT: One of the most appealing features of supramolecular assemblies is their ability to respond to external stimuli due to their noncovalent nature. This provides the opportunity to gain control over their size, morphology, and chemical properties and is key toward some of their applications. However, the design of supramolecular systems able to respond to multiple stimuli in a controlled fashion is still challenging. Here we report the synthesis and characterization of a novel discotic molecule, which self-assembles in water into a singlecomponent supramolecular polymer that responds to multiple independent stimuli. The building block of such an assembly is a $\mathrm{C}_{3}$-symmetric monomer, consisting of a benzene-1,3,5-tricarboxamide core conjugated to a series of natural and non-natural functional amino acids. This design allows the use of rapid and efficient solid-phase

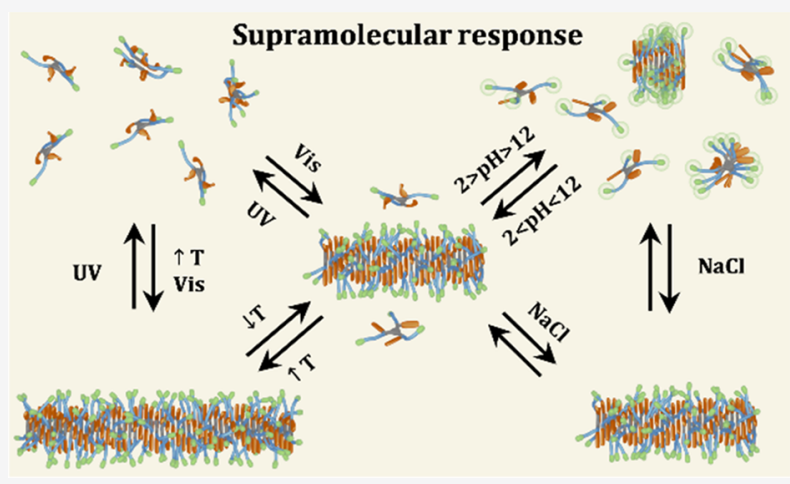
synthesis methods and the modular implementation of different functionalities. The discotic monomer incorporates a hydrophobic azobenzene moiety, an octaethylene glycol chain, and a C-terminal lysine. Each of these blocks was chosen for two reasons: to drive the self-assembly in water by a combination of $\mathrm{H}$-bonding and hydrophobicity and to impart specific responsiveness. With a combination of microscopy and spectroscopy techniques, we demonstrate self-assembly in water and responsiveness to temperature, light, $\mathrm{pH}$, and ionic strength. This work shows the potential to integrate independent mechanisms for controlling self-assembly in a single-component supramolecular polymer by the rational monomer design and paves the way toward the use of multiresponsive systems in water.

\section{INTRODUCTION}

Supramolecular polymers are promising self-assembled structures for a variety of applications. In particular, water-soluble assemblies $^{1}$ show great potential for medical applications such as drug delivery systems, ${ }^{2-6}$ contrast agents, ${ }^{7}$ or hydrogels for tissue engineering. ${ }^{8-11}$

Inspired by naturally existing supramolecular polymers, e.g., actin filaments, chemists attempt to create synthetic materials with life-like properties. In this framework, the design of dynamic structures capable of mimicking the polymerizationdepolymerization equilibrium of biological polymers allows the preparation of functional adaptive materials that change properties in response to a specific stimulus. This responsiveness is interesting at a fundamental level, but is also appealing for a variety of applications. For example, the possibility to disassemble supramolecular drug carriers in a controlled fashion allows for spatiotemporal control over the release of drugs. ${ }^{12}$ Many efforts have been carried out to explore new responsive materials and new strategies to impart responsivity into the monomer design. The groups of Besenius, Schmuck, and Stupp designed systems using $\mathrm{pH}$ as a trigger to change stability and promote disassembly. ${ }^{13-16}$ Yagai and co-workers explored the use of light, temperature, and ultrasound as triggers to control foldability of supramolecular polymers. ${ }^{17-19}$ Lee reported supramolecular nanotubules that undergo a contraction in response to temperature. ${ }^{20}$ Voets reported salttriggered changes in dimensions and cooperativity of the selfassembly. ${ }^{21}$ Moreover, in light of biological applications, the possibility to obtain response to protein binding and enzyme activity has also been studied. ${ }^{22-27}$

Multiresponsivity, i.e., the ability to independently respond to different cues, in aqueous media proved to be more challenging to implement. Using multiple stimuli appears as a promising strategy to achieve fine control over supramolecular polymers' properties. Moreover, it opens the way to logic-gate assemblies able to generate a response only when two stimuli are simultaneously present, increasing selectivity. ${ }^{28-30}$ This is

Received: February 21, 2020

Published: May 12, 2020 


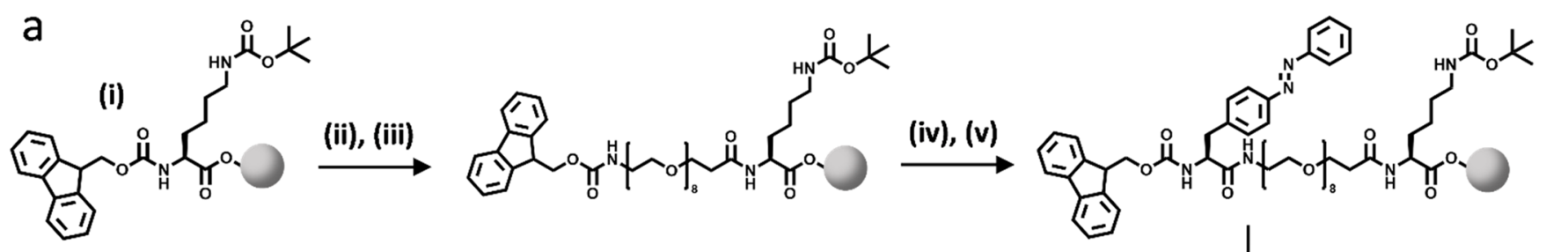

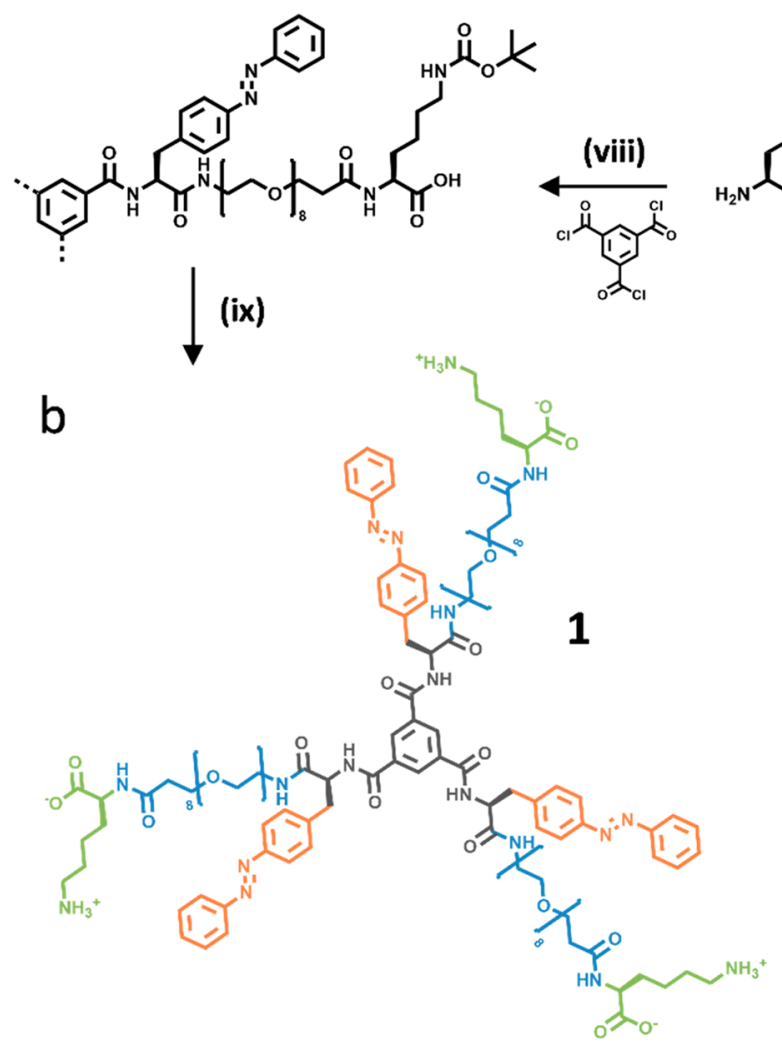

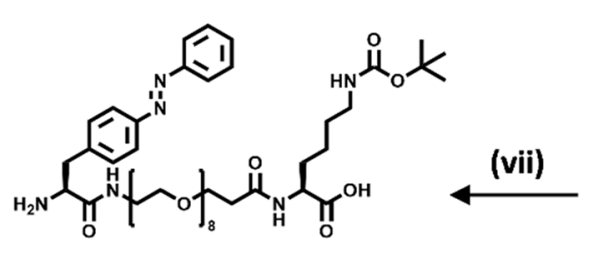

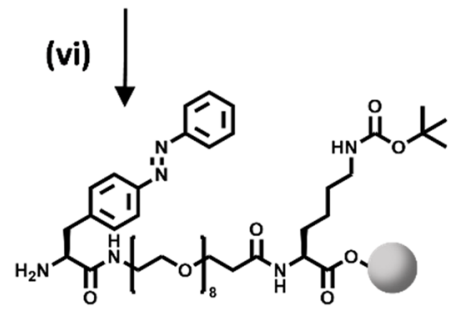

d
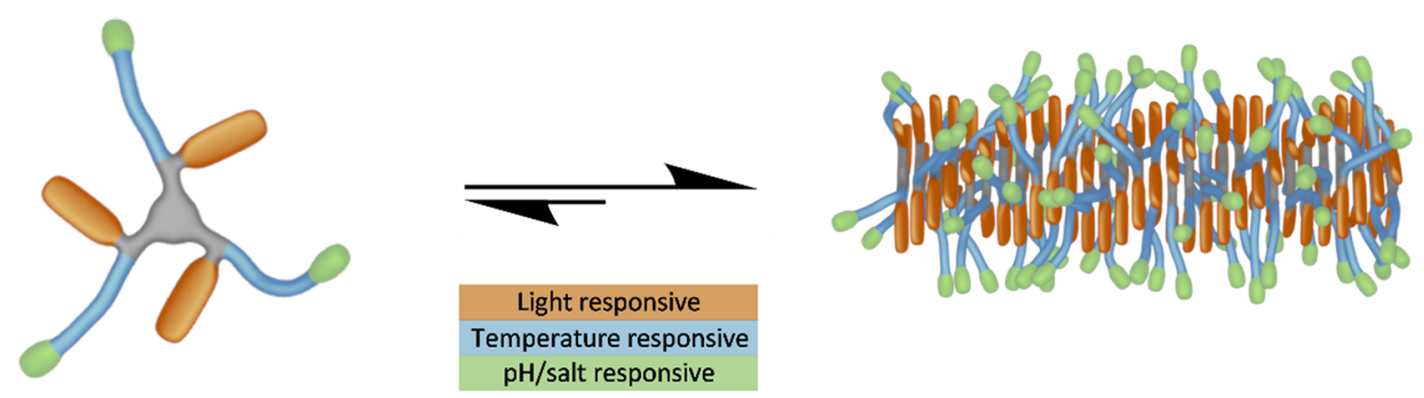

Figure 1. (a) Synthesis of monomer 1: (i) Coupling of Fmoc-Lys(Boc)-OH to 2-chlorotrityl chloride resin (represented by the gray circle), DCM, DIEA, 1 h. (ii) Fmoc removal, 20\% piperidine in DMF. (iii) Coupling of Fmoc-octa(ethylene glycol)-OH, DCM-DMF (1:1), PyBOP, DIEA, 15 h. (iv) Fmoc removal, 20\% piperidine in DMF. (v) Coupling of Fmoc-Azo, DCM-DMF (1:1), PyBOP, DIEA, 15 h. (vi) Fmoc removal, $20 \%$ piperidine in DMF. (vii) Cleavage, TFA 95\% v/v in $\mathrm{H}_{2} \mathrm{O}$. (viii) Core coupling, BT-Cl, $\mathrm{CHCl}_{3}$, DIEA PyBOP, 15 h. (ix) Boc removal, TFA 95\% $\mathrm{H}_{2} \mathrm{O}$. (b) Molecular structure of monomer 1. (c) Molecular structure of monomer 2. (d) Schematic representation of monomer 1 and its selfassembly into supramolecular fibers. The moieties responsible for responsiveness are highlighted in different colors: orange, light responsive moiety; blue, temperature responsive moiety; green, $\mathrm{pH}$ and ionic strength responsive moiety.

particularly interesting in the case of biological applications where the complex cellular environment provides multiple cues to the administered synthetic material.

Few pioneering examples of multiresponsivity have recently been reported. Besenius and co-workers designed a system responsive to $\mathrm{pH}$ and reactive oxygen species, which together with temperature was able to tune the gelating properties of the material. ${ }^{31}$ Bhosale and co-workers reported supra- molecular ribbons with both $\mathrm{pH}$ - and temperature-dependent helicity. ${ }^{32}$ Thayumanavan and co-workers showed the possibility to incorporate different responsive moieties into polymeric amphiphiles through a postpolymerization step, enabling response to light, protein, and redox environment. ${ }^{33}$ $\mathrm{Li}$ and co-workers designed a molecule that self-assembled into fibers, responsive to different ions and temperature. ${ }^{34}$ However, these interesting properties come at the price of 

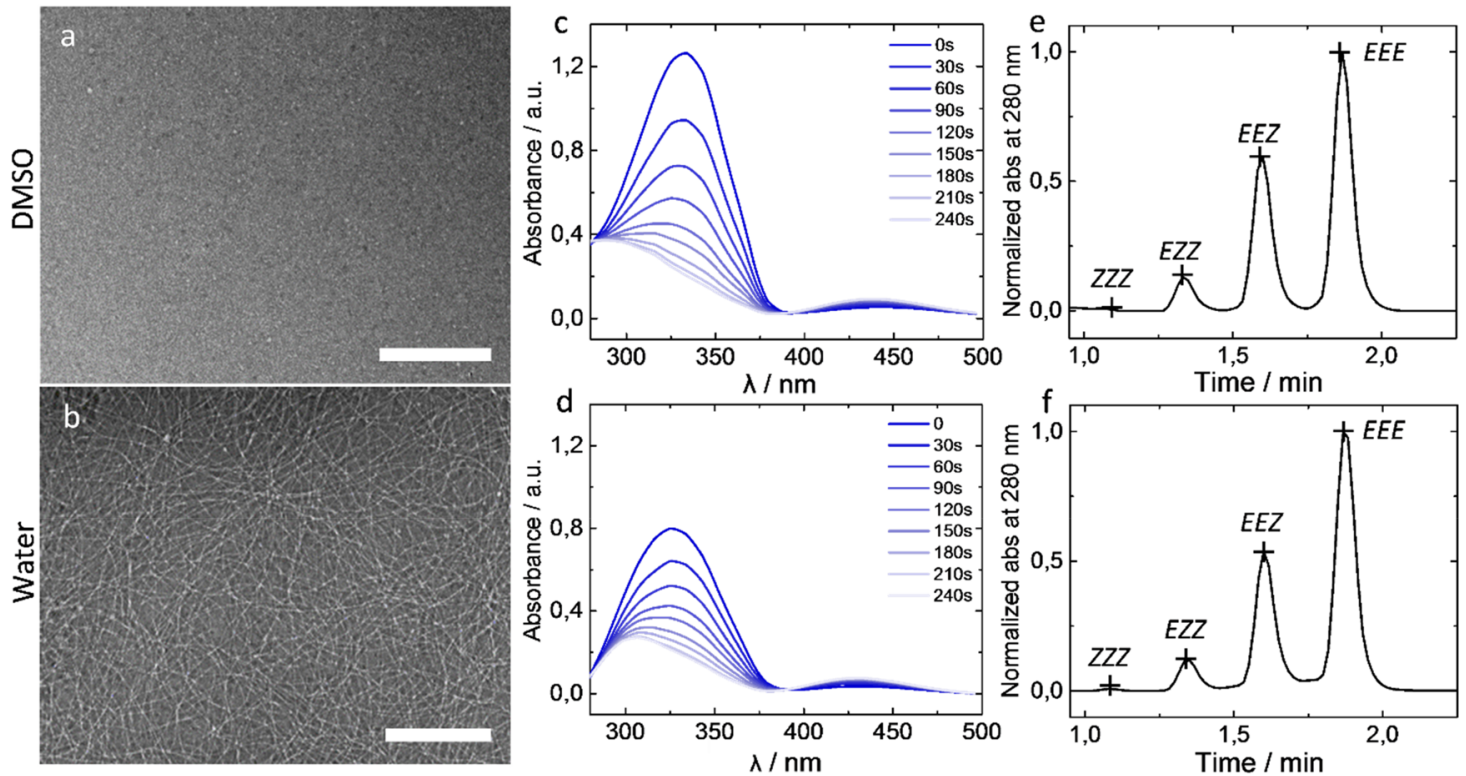

Figure 2. TEM image of $100 \mu \mathrm{M}$ monomer 1 (a) in DMSO and (b) in water (scale bar: $500 \mathrm{~nm}$ ). E-Z photoisomerization of monomer 1 at 25 $\mu \mathrm{M}$ in (c) DMSO and (d) water, with UV $(\lambda=365 \mathrm{~nm})$ irradiations of $30 \mathrm{~s}$. HPLC chromatogram of monomer 1 in (e) DMSO and (f) water at $280 \mathrm{~nm}$ (measured isosbestic point).

complex design, by incorporating either multiple components or synthetically challenging building blocks. Using multiple response mechanisms in the same monomer appears as a promising strategy to achieve fine control over supramolecular polymers.

Here we present the straightforward synthesis of a singlecomponent supramolecular polymer, self-assembled in water, which is capable of independently responding to four stimuli, namely, light, $\mathrm{pH}$, ionic strength, and temperature. This system is designed to offer control over self-assembly through distinct mechanisms, modifying the assembly state in terms of both length and configuration. By a combination of techniques including transmission electron microscopy (TEM), circular dichroism (CD), high-performance liquid chromatography (HPLC), and static light scattering (SLS), we demonstrate that the assembly/disassembly of supramolecular polymers in water is pursued through controlled stimulations.

Our results pave the way toward simpler and highly controllable supramolecular polymers, contributing to the fundamental development of self-assembly in water as well as to their biomedical applications.

\section{RESULTS AND DISCUSSION}

2.1. Molecular Design and Synthesis. The discotic amphiphile was designed to self-assemble and to exhibit responsiveness to light, $\mathrm{pH}$, salt concentration, and temperature. The design was based on a $C_{3}$-symmetrical core, bearing three identical wedges. These wedges were designed to be modular, combining natural and non-natural amino acids chosen to induce self-assembly in water by a combination of hydrophobic effect and $\mathrm{H}$-bonding as well as to imprint specific responsiveness. Notably, the choice of amino acid building blocks allows for a modular approach by using solidphase synthesis. The synthetic route toward and structure of monomer 1 are shown in Figure $1 \mathrm{a}$ and $\mathrm{b}$.

To promote self-assembly, benzene-1,3,5-tricarboxamide (BTA) was chosen as a core to drive aggregation due to the well-known H-bonding behavior. ${ }^{35}$ The BTA core is function- alized with three amphiphilic wedges composed of amino acid modules that promote assembly in water and induce responsivity as well (Figure 1d). A non-natural azobenzene amino acid (L-phenylalanine- 4 '-azobenzene, Figure $1 \mathrm{~b}$ highlighted in orange) was placed as the innermost block of the wedge to enhance self-assembly by increasing hydrophobicity and by shielding the intermolecular $\mathrm{H}$-bonds of the BTA core from water. At the same time, the azobenzene moiety imparts light responsivity through the well-known $E-Z$ isomerization. Azobenzenes are a well-established class of molecular photoswitches in the fields of smart materials and photocontrol of biological systems because of some favorable characteristics, such as design flexibility, ease of synthesis, large changes in geometry upon isomerization, high quantum yields, and low photobleaching rates. ${ }^{36,37}$ We hypothesized that the $E$ form favors assembly due to its planar hydrophobic nature, while the nonplanar and more polar $Z$ form will destabilize monomer stacking and increase monomer solubility. ${ }^{38}$ The second module of the wedge is an octa(ethylene glycol) amino acid (Figure $1 \mathrm{~b}$, highlighted in blue), which grants flexibility and solubility in water, while it confers thermal responsivity due to its temperature-dependent hydrophilicity. ${ }^{39-42}$ Finally, a Cterminal lysine (Figure $1 \mathrm{~b}$, highlighted in green) was added to enhance water solubility owing to the charged groups and induce the ampholytic character of this particular amino acid, which can result in dual $\mathrm{pH}$ and ionic strength response.

The described monomer was designed to be synthesized through standard solid-phase peptide synthesis (SPPS), offering a modular and straightforward synthesis. All building blocks are commercially available or are synthesized as fluorenylmethyloxycarbonyl (Fmoc)-protected amino acids, allowing to iteratively repeat the same synthetic steps (Figure 1a). Following an Fmoc strategy, the wedge is grown sequentially on the resin from $\mathrm{C}$-terminus to $\mathrm{N}$-terminus using the proper Fmoc-protected building blocks. Both octa(ethylene glycol) and azobenzene couplings were not standard and were optimized (see SI). After its completion (steps i to vi, Figure 1a), the wedge was cleaved from the resin 

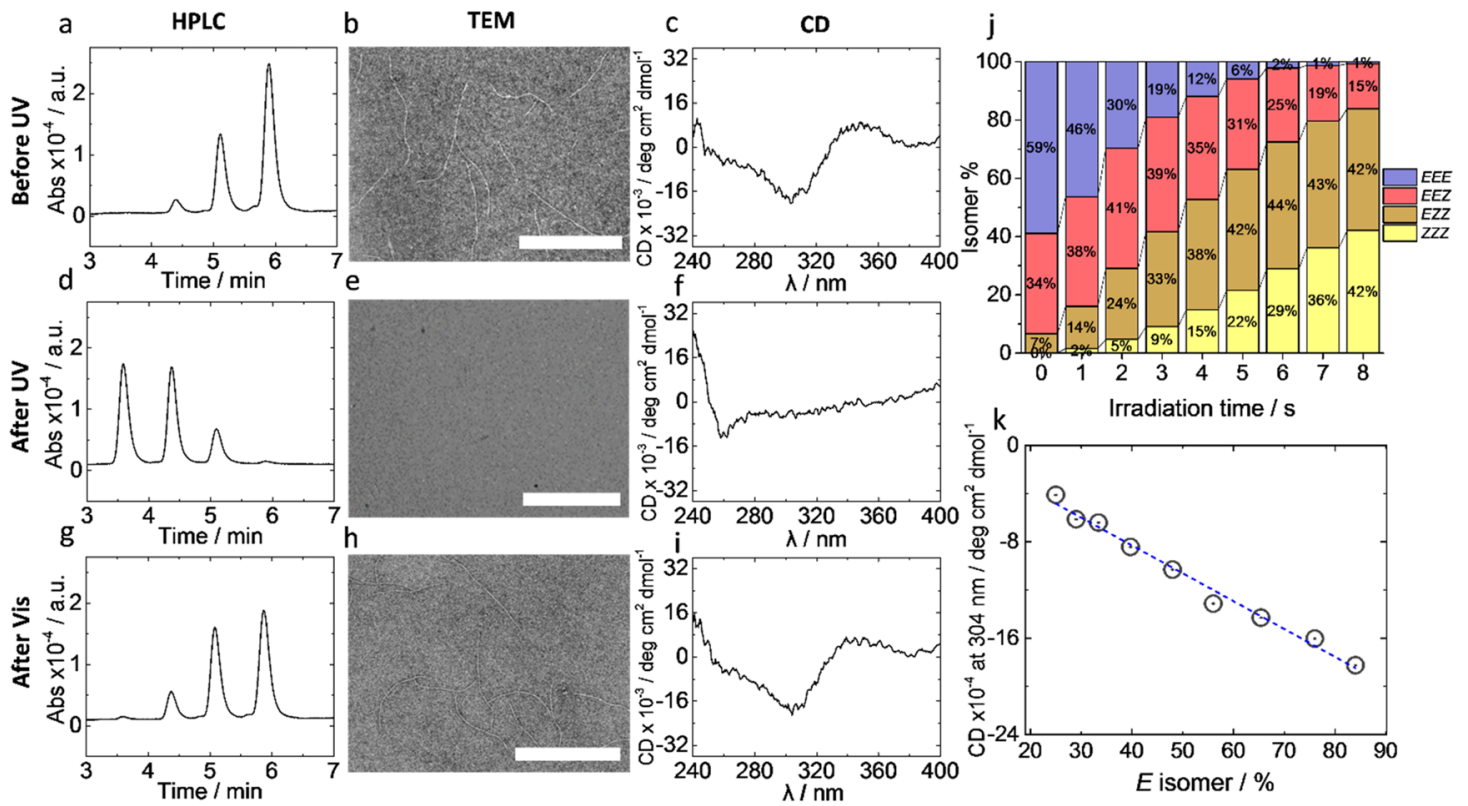

Figure 3. HPLC-UV at $280 \mathrm{~nm}$ of the sample at $25 \mu \mathrm{M}$ (a) before UV, (b) after UV irradiation ( $365 \mathrm{~nm}, 8 \mathrm{~s} 100 \%$ at $1000 \mathrm{~mA}$ of the LED intensity), and (c) after blue light $(455 \mathrm{~nm}, 10 \mathrm{~s}, 100 \%$ at $1000 \mathrm{~mA}$ of the LED intensity). TEM of the sample at $25 \mu \mathrm{M}$ (d) before UV, (e) after $\mathrm{UV}$, and (f) after blue light irradiation (scale bar: $500 \mathrm{~nm}$ ). CD of the sample at $25 \mu \mathrm{M}$ (g) before $\mathrm{UV}$, (h) after $365 \mathrm{~nm}$ irradiation for $8 \mathrm{~s}$, and (i) after $455 \mathrm{~nm}$ irradiation for $10 \mathrm{~s}$. (j) HPLC-UV analysis of isomer distribution at different UV irradiation times. (k) CD at $304 \mathrm{~nm}$ at different $E$ isomer \% (the line was added to guide the eye).

keeping the tert-butyloxycarbonyl (Boc) protecting group (step vii) and subsequently purified through $\mathrm{H}_{2} \mathrm{O}-\mathrm{DCM}$ extraction (Figures S2, S3).

The final step, consisting of the convergent coupling to form the BTA, was performed in solution. The wedge was reacted with a benzene tricarbonyl chloride, thereby forming the Bocprotected monomer 1 (step viii). Boc deprotection was performed, and the final product was purified through reversed-phase HPLC (step ix). The purity and molecular weight of the desired product were confirmed using reversedphase HPLC-MS, MALDI, and ${ }^{1} \mathrm{H}$ NMR (Figure S6). Detailed synthetic procedures and material characterizations are provided in the SI.

This synthetic strategy allows the facile and precise control over the structure by using SPPS. The use of properly protected natural and non-natural amino acids reduces the number of necessary purifications in comparison with insolution synthesis. Moreover, the sequence, the chemical nature, and the number of amino acids can be changed without modifying the synthetic procedure. This is a great advantage in light of structure optimization as well as for the generation of libraries of compounds.

2.2. Self-Assembly and Spectroscopic Behavior. To investigate the self-assembly behavior, monomer 1 was first dissolved in DMSO at a concentration of $2.5-10 \mathrm{mM}$, in which it is molecularly dissolved, eliminating any possible preexisting aggregates. Next, the concentrated stock solution was diluted with Milli-Q water to obtain a $25-100 \mu \mathrm{M}$ monomer, triggering the self-assembly. Unless stated otherwise, a temperature cycle $\left(70{ }^{\circ} \mathrm{C}\right.$ for $1 \mathrm{~h}+24 \mathrm{~h}$ at $\left.\mathrm{rt}\right)$ was applied to obtain a reproducible equilibrium.

TEM showed the absence of aggregates in DMSO (Figure 2a), confirming, together with the resolved ${ }^{1} \mathrm{H}$ NMR, the molecularly dissolved state in this solvent. In water, monomer 1 assembled into $\mu \mathrm{m}$-long and flexible fibers as shown in Figure $2 \mathrm{~b}$. A quantitative analysis of the TEM images reveals a diameter of $6.48 \pm 1.15 \mathrm{~nm}$, in good agreement with other reported water-soluble BTAs. ${ }^{43}$

Initially, two discotic amphiphiles were synthesized following the same design, differing only in the azobenzene amino acid. In monomer 1 (Figure $1 \mathrm{~b}$ ), which contains a $\mathrm{L}$ phenylalanine- $4^{\prime}$-azobenzene, the azobenzene is placed as a side chain of the wedge. In monomer 2 (Figure 1c), which comprises a [3-(3-aminomethyl)phenylazo]phenylacetic acid, the azobenzene is placed as backbone of the wedge. Since the azobenzene moiety is in close proximity to the core in both cases, very different behaviors can be expected for monomer 1 (Figure 1b) and 2 (Figure 1c). Remarkably, despite the similar structures of both monomers, monomer 2 did not selfassemble under any of the tested conditions of concentration, temperature, and light irradiation. We hypothesize that the orientation and proximity to the core of the azobenzene moiety of monomer 2 prevent effective stacking. All the work reported in the following sections will therefore focus exclusively on monomer 1 .

In order to characterize the monomer isomerization state and switching ability inside the assemblies, we performed UVvis spectroscopy and HPLC of monomer 1 prepared in in both DMSO and water (Figure 2). Azobenzene has a characteristic absorbance spectrum that allows studying the relative population of the two isomers, namely, for the $E$ isomer $\lambda_{\max }$ $=330 \mathrm{~nm}$ and for $Z \lambda_{\max }=430 \mathrm{~nm}$. The UV-vis spectra were recorded in DMSO (nonstacked monomer) and milli-Q (mainly stacked monomer) at different UV irradiation $(\lambda=$ $365 \mathrm{~nm}$ ) times (Figure $2 \mathrm{c}$ and $\mathrm{d}$ ). Initially, one absorbance peak was visible at $\lambda=330 \mathrm{~nm}$, corresponding to the $E$ configured azobenzene, the most stable isomer at standard conditions. Upon UV irradiation, the E-azobenzene peak decreases while the $Z$-azobenzene peak at $440 \mathrm{~nm}$ appears, resulting in two isosbestic points, at 280 and $387 \mathrm{~nm}$, indicating that the isomerization took place. Moreover, we were able to compare the kinetics of photoisomerization by 
plotting the ratio between the peaks at 430 and $330 \mathrm{~nm}$ in time, which as a first approximation we define as the " $E / Z$ ratio". This shows a maximum conversion in less than $5 \mathrm{~min}$ and concludes that the azobenzene moiety can efficiently isomerize as a free molecule in solution (DMSO) and in the assembled state (water) (Figure S9). Interestingly, the $Z$ configuration is stable when kept in the dark at $25{ }^{\circ} \mathrm{C}$ at least for $24 \mathrm{~h}$ (Figure S10), confirming the measured isomer distribution is not affected by the thermal back-isomerization. This is an important feature to consider when using photochromic ligands, especially for functional biological assays. $^{44,45}$ Finally, monomers in the $Z$ configuration can isomerize back to E-azobenzene by irradiating with blue light $(455 \mathrm{~nm})$. It was possible to reproduce 10 isomerization cycles, showing no signs of fatigue in both DMSO and water (Figure S11).

Altogether, these observations highlight a number of crucial features of our system. First, the azobenzenes can isomerize both in the molecularly dissolved state and inside the fibers. This is far from trivial, as the steric hindrance and interactions inside the assembly can prevent isomerization. ${ }^{46-48}$ Second, the very slow thermal recovery allows the photocontrol of the system in time. Lastly, the system is fully reversible and can undergo multiple photoisomerization cycles.

Interestingly, even though spectroscopically we differentiate two states $(E$ and $Z$ ), the monomer can actually be found in four different configurations. Considering that each monomer has three independent azobenzene moieties, which can be either $E$ or $Z$, the monomer can be found as EEE, EEZ, EZZ, and ZZZ. Indeed, the analysis of samples of $\mathbf{1}$ in both DMSO and water by HPLC-UV-MS (Figure 2e,f) displayed four peaks, in agreement with previous reports. ${ }^{43}$ HPLC also allowed the analysis of the relative distribution in population of the isomers, which is valuable information since the isomers' distribution can have an impact on the self-assembly. ${ }^{49}$ As shown in Figure 2e,f, monomers start mostly with azobenzenes in the $E$ configuration (EEE), while a significant population of $E E Z$ is present in the nonirradiated state. UV irradiation will change the distribution of these populations, which can be recovered through irradiation with blue light $(455 \mathrm{~nm})$. With these premises we proceed in studying the responsive behavior of these fibers.

2.3. Light Responsive Self-Assembly. As discussed, we hypothesized that the $E-Z$ isomerization of an azobenzene placed close to the BTA would disrupt the self-assembly, due to the decreased propensity of the bent $Z$-azobenzenes to stack and the higher solubility in water. ${ }^{38,50}$ Thus, UV irradiation would result in dissolution of the fibers, and visible irradiation would promote fiber reassociation.

To confirm this hypothesis, a combination of HPLC, TEM, and $\mathrm{CD}$ was used. In Figure $3 \mathrm{a}-\mathrm{i}$ we report a comparison among samples before/after irradiation with UV light and after irradiation with blue light, making use of the three different techniques. The pristine sample contains a large fraction of EEE monomer (about 60\%), as indicated by HPLC (Figure $3 a)$, which results in the assembly of long fibers as observed by TEM (Figure 3b). Due to the chirality of the azobenzenecontaining amino acid, a helical stack with a preferred helicity is formed, which can be followed by $\mathrm{CD} .{ }^{51}$ Figure $3 \mathrm{c}$ shows the CD spectrum of the fibers, revealing a band at $260-380 \mathrm{~nm}$, centered at $330 \mathrm{~nm}$, corresponding to the stacking of the azobenzene moieties.
After UV irradiation several dramatic changes can be observed. First, significant isomerization takes place as shown by HPLC. Before UV treatment the photostationary state is primarily (>90\%) composed of EEE and EEZ monomers, while $Z$-rich monomers are the majority species (EZZ $42 \%$ and $Z Z Z$ $42 \%)$ after UV irradiation. This photoisomerization is accompanied by the disappearance of the CD peak at 330 $\mathrm{nm}$ (Figure 3f), indicating loss of helical order, and most strikingly by the complete disappearance of long fibrillar aggregates in the TEM characterization (Figure 3e). These observations showed that the $E-Z$ isomerization of the azobenzene moieties results in the disassembly of the supramolecular polymers. Notably, after irradiation with blue light, recovery of the initial supramolecular polymers was obtained: HPLC shows that the population of isomers is reverted (Figure 3g), the CD signal is restablished (Figure 3i, and TEM again shows the presence of fibers of the same length and morphology (Figure 3h). Therefore, the material designed here is photoresponsive, the response is reversible, and a correlation between monomer configuration and assembly state is established.

To demonstrate that this switch is not abrupt but is gradual and therefore controllable, we performed a kinetic study to evaluate the isomer distribution and the assembly state at different irradiation times by HPLC and CD. In Figure $3 j$ a plot of the distribution of isomers after stepwise UV irradiation is presented. Initially, the system contains predominantly monomers in EEE configuration, while very gradually $Z$-forms are enriched. This shows the potential to precisely control relative abundance of the isomers by irradiation time. Interestingly, the $\mathrm{CD}$ signal, and therefore the amount of monomers in a helical fiber, is proportional to the amount of $E$ form of monomers (Figure 3k). This tendency points out that the crucial feature for the self-assembly of the monomers is the amount of $E$ isomers. This indicates that there is a constructive interaction between azobenzenes in $E$ inside the assembly, favoring the stacking of EEE, over EEZ or EZZ.

These results demonstrate a strong relationship between self-assembly and concentration of the EEE isomer, as well as fine-tuning the self-assembly by UV irradiation. By this means, specific degrees of assembly are accessible by controlling the concentration of the EEE monomer (Figures 3k, S12).

In brief, we demonstrated by a combination of HPLC, TEM, and $\mathrm{CD}$ that self-assembly in our system can be finely modulated by irradiation with UV and blue light to tune the isomer population distribution.

2.4. Temperature Responsiveness. Due to the weak nature of the noncovalent bonding, supramolecular polymers generally display temperature-dependent behavior, typically disassembling at high temperatures, a property that is often used to study the self-assembly mechanism. ${ }^{52}$ However, it has also been extensively reported that polyethylene glycolcontaining supramolecular structures exhibit a different temperature response in water, showing a transition to an enhanced aggregation state at higher temperatures due to entropic effects. ${ }^{31,53-56}$ Aiming to elucidate the temperature responsiveness of our system, we studied the assembly state at different temperatures by TEM, CD, and SLS.

First, a temperature cycle $\left(25-75-25{ }^{\circ} \mathrm{C}\right)$ was performed on the sample, and TEM images were taken at the three different temperature points. Before heating, TEM showed few fibers per field with a length in the range of $300 \mathrm{~nm}$ (Figure $4 a)$. When increasing the temperature to $75^{\circ} \mathrm{C}$, an increase in 

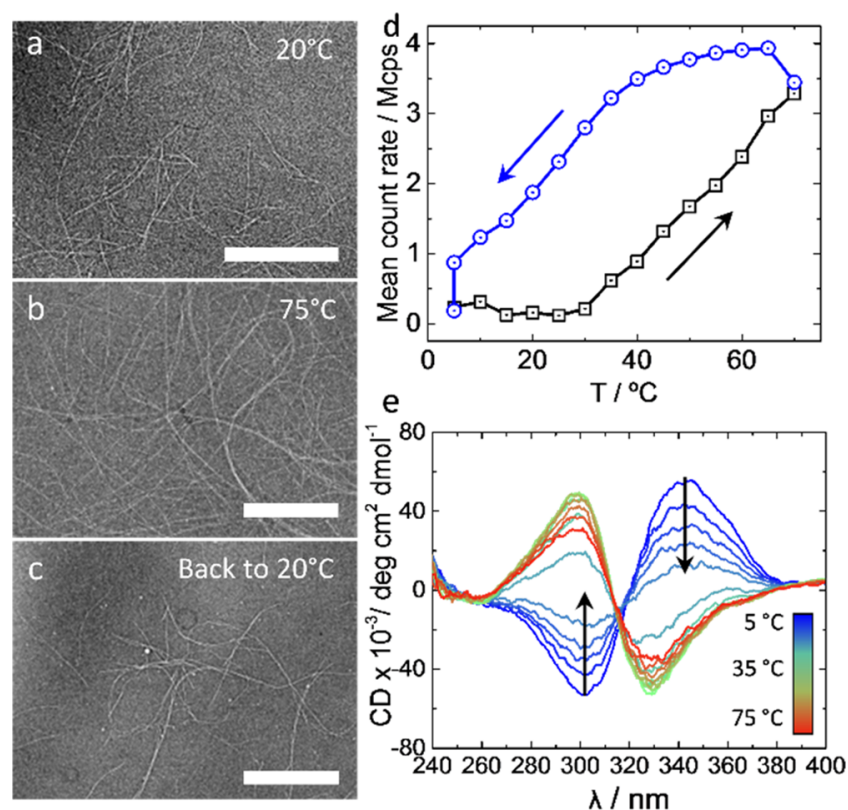

Figure 4. TEM of monomer 1 at $20 \mu \mathrm{M}$ at (a) $20^{\circ} \mathrm{C}$, (b) $75^{\circ} \mathrm{C}$, and (c) $20^{\circ} \mathrm{C}$ after cooling from $75^{\circ} \mathrm{C}$. (d) SLS temperature cycle on the sample at $100 \mu \mathrm{M}$ at $60^{\circ} \mathrm{C} / \mathrm{h}$ measuring in steps of $5{ }^{\circ} \mathrm{C}$ (the line was added to guide the eye). (e) $\mathrm{CD}$ heating ramp experiment on the sample at $25 \mu \mathrm{M}$ at $60{ }^{\circ} \mathrm{C} / \mathrm{h}$, measuring in steps of $5{ }^{\circ} \mathrm{C}$.

both number and length of the fibers can be clearly observed (Figure 4b). After cooling and subsequent equilibration for 24 $h$, the number of fibers decreased again, resembling the situation before heating (Figure 4c) and strongly suggesting a reversible character of the response. In all cases, the sample preserved the fiber-like shape and diameter, although an increase in number, length, and degree of entanglements can be observed at the higher temperature.

To corroborate this, a temperature cycling experiment was performed with SLS (Figure $4 \mathrm{~d}$ ). We observed a very low scattering intensity (close to the limit of detection) at low temperatures. However, a linear increase was obtained ramping up from $25{ }^{\circ} \mathrm{C}$ to $30^{\circ} \mathrm{C}$ to $70{ }^{\circ} \mathrm{C}$. This trend is also reversible, matching with TEM results, but shows a hysteresis because of the long time required to reach equilibrium (S13). In order to confirm that the increase in scattering intensity is due to an increase in aggregation and not due to an increase in the refractive index at higher temperatures, we made use of the UV response of the system. We proceeded to warm the sample at $40{ }^{\circ} \mathrm{C}$ and equilibrate, obtaining the increase in scattering, and then we irradiated the sample with UV light. The experiment resulted in a decrease of the scattering signal to detection limits (S13), for which the only explanation can be a loss in aggregation. Thus, the UV irradiation can trigger the disassembly even when the polymerization is enhanced.

To further investigate the mechanism of this phenomenon, a temperature cycling experiment was performed also with $\mathrm{CD}$, showing two transitions: first, a signal inversion for the stacked azobenzene from 5 to $40{ }^{\circ} \mathrm{C}$ and, second, a decrease in signal intensity above $50^{\circ} \mathrm{C}$ (Figures 4e, S14). The spectrum showed a positive Cotton effect between 260 and $380 \mathrm{~nm}$ (corresponding to the azobenzene absorbance) below rt, which changed to a negative Cotton effect at $20-25{ }^{\circ} \mathrm{C}$. On the contrary the $\mathrm{CD}$ signal corresponding to the BTA cores $\left(\lambda_{\max }=220 \mathrm{~nm}\right.$, only a peak shoulder can be observed, S15) did not seem altered even though the cutoff wavelength of DMSO prevented a detailed analysis. Therefore, a full helix inversion seems unlikely, while a change in the packing and helicity of the azobenzenes along the fibers seems responsible for the observed transition. The signal kept increasing until 50 ${ }^{\circ} \mathrm{C}$ and then started decreasing in a reversible manner (S14). This inflection could imply a "classical" loss in aggregation due to temperature-induced depolymerization.

Interestingly, this unusual temperature-enhanced polymerization is the consequence of the synergistic response of the azobenzene moiety and the octa(ethylene glycol) chain together. First, temperature modifies the distribution of $E$ and $Z$ isomers of the azobenzene moiety, favoring the more thermodynamically stable EEE isomer at high temperatures (S14) and thus increasing aggregation. However, this increase in the concentration $(+20 \%)$ on its own cannot explain the increased SLS signal $(+2000 \%)$ or the signal inversion observed in CD spectroscopy. Second, octa(ethylene glycol) hydrophobicity is increased upon heating because of loss of solvating water molecules, ${ }^{40,42}$ thereby increasing the driving forces for self-assembly driving forces. We hypothesize that the monomer rearrangement inside the fibers is related to the desolvation of octa(ethylene glycol), because it leads to an increased hydrophobicity and a reduced steric hindrance between octa(ethylene glycol) chains. Analogous results have been reported before in similar scenarios. ${ }^{20}$

Together, these two effects are amplified. The temperature increases at the same time as the hydrophobicity of each monomer and the distribution of azobenzene moieties in the $E$ configuration. Therefore, there are more monomers able to stack than at rt and their hydrophobicity is higher. The sum brings the systems to the highest aggregation state at 40-50 ${ }^{\circ} \mathrm{C}$.

Summarizing, we have a supramolecular system with a reversible response to temperature, enhancing monomer aggregation above room temperature and changing the internal conformation of the lateral chain packing. Furthermore, even when the polymerization is enhanced, the assemblies remain responsive to light. Considering that the kinetics of the photoisomerization is much faster than the kinetics of the thermal back-isomerization, the light response dominates over the temperature response.

2.5. $\mathrm{pH}$ and Ionic Strength Responsiveness. Previous work highlighted that the stability of a supramolecular polymer can be affected by the repulsion between charged monomers. ${ }^{57}$ An elegant strategy to design responsive systems using this phenomenon consists of introducing specific groups, whose protonation, and consequently charge, depends on $\mathrm{pH}^{13}$

Inspired by this work and aiming for an ampholytic behavior in a single component, we included a C-terminal lysine in our design, exposing a carboxylic acid and a primary amine at the periphery of the monomer. Considering the $\mathrm{p} K_{\mathrm{a}}$ 's of both amino (10.79) and carboxylic groups (2.20), we can delimit three $\mathrm{pH}$ ranges in which the net charge of the discotic monomer undergoes significant variations. Approximately, between $\mathrm{pH} 3.9$ and $\mathrm{pH} 9.6$ monomers are zwitterionic, comprising three carboxylate groups and three ammonium groups, with a net charge of 0 (Figure S16). When approaching $\mathrm{pH} 2.2$, the carboxylate groups become protonated, resulting in a net positive charge, which would destabilize the aggregates and promote disassembly. A similar process would happen when approaching $\mathrm{pH} \mathrm{12,} \mathrm{when} \mathrm{the} \mathrm{ammonium} \mathrm{moieties} \mathrm{are}$ deprotonated, resulting in a net negative charge. Therefore, the 

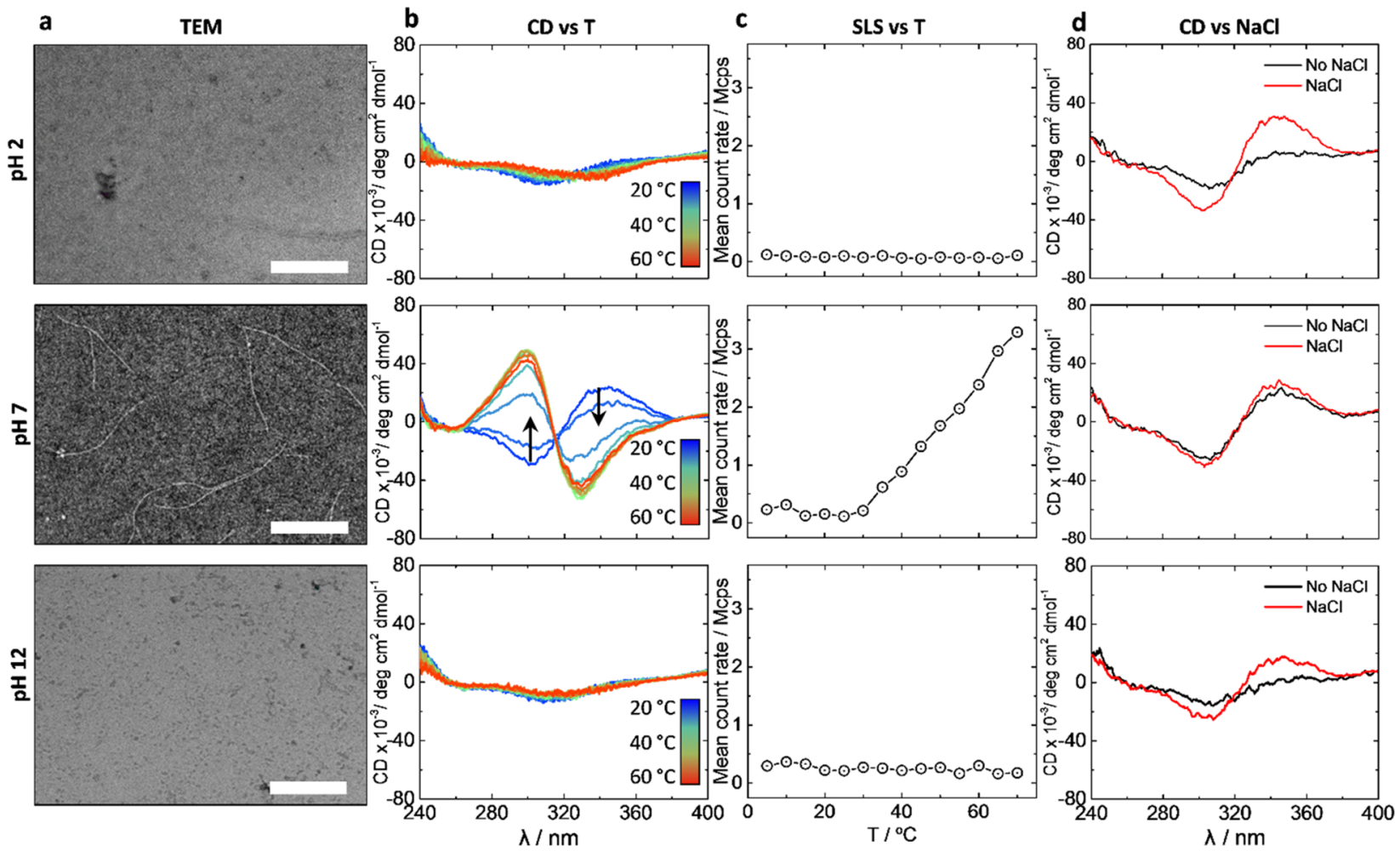

Figure 5. TEM image of monomer 1 at $100 \mu \mathrm{M}$ (a) at $\mathrm{pH} 2.0 \pm 0.2,7.0 \pm 0.2$, and $11.6 \pm 0.2$ (scale bar: $250 \mathrm{~nm}$ ). CD heating experiment at 25 $\mu \mathrm{M}(\mathrm{b})$ at $\mathrm{pH} 2.2 \pm 0.2,7.2 \pm 0.8$, and $12.0 \pm 0.2\left(60^{\circ} \mathrm{C} / \mathrm{h}\right.$, measuring in steps of $\left.5^{\circ} \mathrm{C}\right)$. SLS heating experiment at $100 \mu \mathrm{M}(\mathrm{c})$ at $\mathrm{pH} 2.0 \pm 0.2$, $7.0 \pm 0.2$, and $11.6 \pm 0.2\left(60^{\circ} \mathrm{C} / \mathrm{h}\right.$ measuring in steps of $5^{\circ} \mathrm{C}$ ) (the line was added to guide the eye). $\mathrm{CD}$ at $5^{\circ} \mathrm{C}$ with and without $\mathrm{NaCl} 150 \mathrm{mM}$ (d) at $\mathrm{pH} 2.2 \pm 0.2,7.2 \pm 0.8$, and $12.0 \pm 0.2$.

system can evolve from a zwitterionic monomer, where the assembly would be favored through potential ionic bridges between stacked discs, to electrostatic repulsion-induced disassembly.

In order to demonstrate that this ampholytic behavior has an impact on self-assembly, we performed a series of experiments including TEM, CD, and SLS. We prepared samples at three different $\mathrm{pH}$ values and compared the self-assembly of zwitterionic monomers $(+3 /-3$ at $\mathrm{pH} 7.2 \pm 0.8)$ with positively charged monomers $(+3$ at $\mathrm{pH} 2.2 \pm 0.2)$ and negatively charged monomers $(-3$ at $\mathrm{pH} 12.0 \pm 0.2)$. These $\mathrm{pH}$ values were chosen according to the expected maximum of population of each charged species (Figure S16).

TEM revealed the formation of fibers at neutral $\mathrm{pH}$, while very few were observed at low $\mathrm{pH}$ and none at high $\mathrm{pH}$ (Figure 5a). This indicates that the repulsion at high and low $\mathrm{pH}$ values is sufficient to destabilize the aggregates, resulting in monomers or small aggregates. In order to reinforce this result and explore the combination of the temperature and $\mathrm{pH}$ responses, a temperature ramping experiment with $\mathrm{CD}$ and SLS was performed at the different $\mathrm{pH}$ values. Very low signal was obtained for nonzwitterionic samples using $\mathrm{CD}$, showing also a very weak temperature response (Figure $5 b$ ). This can be attributed to the few monomers still zwitterionic and, hence, able to aggregate. SLS showed a low count rate that did not increase upon heating (Figure 5c), indicating no (significant) aggregation, confirming the TEM and CD results. In addition, we irradiated the samples with UV light at the different $\mathrm{pH}$ 's to demonstrate the compatibility of the two responsiveness (S17), showing higher degrees of disassembly. These indications altogether support the $\mathrm{pH}$ responsiveness of our fibers and the existence of three $\mathrm{pH}$ windows in which the system's net charge changes, producing a dramatic change in aggregation. Furthermore, it demonstrated that the temperature effect on the self-assembly at extreme $\mathrm{pH}$ 's, where the increased hydrophobicity due to desolvation of the octaethylene glycol chain competes against the electrostatic repulsion, is too subtle to make a change. Thus, in this scenario the $\mathrm{pH}$ response dominates over the temperature response.

Previous reports have also shown that ionic strength can modulate monomer repulsion through shielding of charges. ${ }^{56}$ Here, we tested if our fibers respond to changes in ionic strength in the three $\mathrm{pH}$ windows. In particular, we added $\mathrm{NaCl}$ at a physiological concentration $(150 \mathrm{mM})$ with the purpose of shielding the charges. In Figure $5 \mathrm{~d}$ we compare CD spectra from samples at $\mathrm{pH} 2.2,7.2$, and 12.0, with and without salt. In all cases, we observe an increase in $\mathrm{CD}$ signal, associated with an increased aggregation. Under the acidic and basic conditions, the influence is more pronounced, because the sample changes from a disassembled to an assembled state. Interestingly, we did this experiment at two different temperatures, 5 and $20{ }^{\circ} \mathrm{C}$, observing a reduced signal at 20 ${ }^{\circ} \mathrm{C}$ due to the proximity to the signal inversion temperature (Figure S18). These results demonstrate that the repulsion can be modified by the ionic strength, confirming the mechanism of the responsiveness to $\mathrm{pH}$ and its reversibility, and indicate the temperature response remains.

\section{CONCLUSIONS}

In conclusion, we demonstrated the possibility to condense different response mechanisms in single-component supra- 
Monomer response
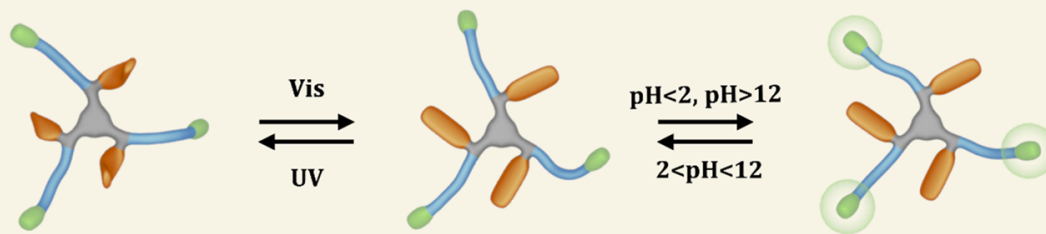

\section{Supramolecular response}

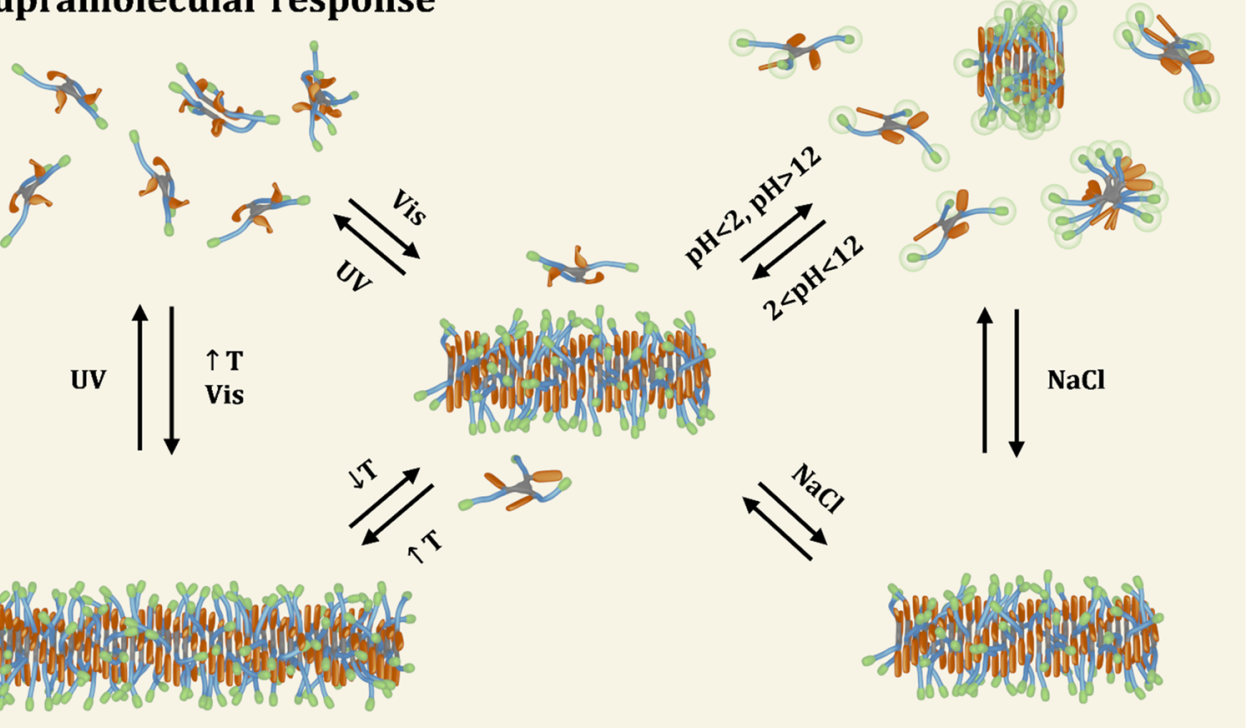

Figure 6. Schematic representation of the system. Above, molecular responsiveness to light and $\mathrm{pH}$. Below, supramolecular responsiveness to light, $\mathrm{pH}$, ionic strength, and temperature.

molecular polymers through a rational monomer design. Following a modular synthesis, we incorporate moieties in the monomer design that, simultaneously, drive the selfassembly and introduce responsiveness to different stimuli (Figure 6). Our system responds in a controlled and reversible fashion to light, temperature, $\mathrm{pH}$, and ionic strength, modulating the assembly-disassembly equilibrium. By these means, we describe a system with multiple equilibria (Figure 6) in which each state is accessible through different pathways, applying the stimuli either orthogonally or in combination, thereby facilitating a sophisticated degree of control.

Our results pave the way toward effective and highly controllable supramolecular materials in which the responsiveness is fully imprinted in a single monomer. This is especially interesting for biological applications, such as drug delivery or tissue engineering, where controlling the material performance in a complex environment is challenging.

\section{ASSOCIATED CONTENT}

\section{(3) Supporting Information}

The Supporting Information is available free of charge at https://pubs.acs.org/doi/10.1021/jacs.0c02067.

Experimental procedure for the synthesis of $\mathbf{1}$ and $\mathbf{2}$ as well as analytical, spectral, and self-assembly characterization data (PDF)

\section{AUTHOR INFORMATION}

\section{Corresponding Authors}

Lorenzo Albertazzi - Institute for Bioengineering of Catalonia (IBEC), The Barcelona Institute of Science and Technology
(BIST), Barcelona 08036, Spain; Department of Biomedical Engineering, Institute of Complex Molecular Systems (ICMS), Eindhoven University of Technology (TUE), Eindhoven 5612

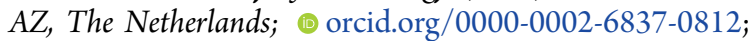
Email: 1.albertazzi@tue.nl, lalbertazzi@ibecbarcelona.eu

Silvia Pujals - Institute for Bioengineering of Catalonia (IBEC), The Barcelona Institute of Science and Technology (BIST), Barcelona 08036, Spain; Department of Electronics and Biomedical Engineering, Faculty of Physics, Universitat de Barcelona, Barcelona 08011, Spain; Email: spujals@ ibecbarcelona.eu

\section{Authors}

Edgar Fuentes - Institute for Bioengineering of Catalonia (IBEC), The Barcelona Institute of Science and Technology (BIST), Barcelona 08036, Spain

Marieke Gerth - Laboratory of Self-Organizing Soft Matter, Department of Chemical Engineering and Chemistry \& Institute of Complex Molecular Systems (ICMS) and Laboratory of Physical Chemistry, Department of Chemical Engineering and Chemistry, Eindhoven University of Technology (TUE), Eindhoven 5612 AZ, The Netherlands

José Augusto Berrocal - Adolphe Merkle Institute, Polymer Chemistry and Materials, University of Fribourg, 1700 Fribourg, Switzerland; (1) orcid.org/0000-0003-3435-8310

Carlo Matera - Institute for Bioengineering of Catalonia (IBEC), The Barcelona Institute of Science and Technology (BIST), Barcelona 08036, Spain; Network Biomedical Research Centre in Biomaterials, Bioengineering and Nanomedicine (CIBER-BBN), Madrid 28029, Spain; ( ) orcid.org/0000-0001-6939-3859 
Pau Gorostiza - Institute for Bioengineering of Catalonia (IBEC), The Barcelona Institute of Science and Technology (BIST), Barcelona 08036, Spain; Network Biomedical Research Centre in Biomaterials, Bioengineering and Nanomedicine (CIBER-BBN), Madrid 28029, Spain; Catalan Institution for Research and Advanced Studies (ICREA), Barcelona 08011, Spain; (1) orcid.org/0000-0002-7268-5577

Ilja K. Voets - Laboratory of Physical Chemistry, Department of Chemical Engineering and Chemistry, Eindhoven University of Technology (TUE), Eindhoven 5612 AZ, The Netherlands; (1) orcid.org/0000-0003-3543-4821

Complete contact information is available at: https://pubs.acs.org/10.1021/jacs.0c02067

\section{Notes}

The authors declare no competing financial interest.

\section{ACKNOWLEDGMENTS}

This work was financially supported by the EURONANOMED (NANOVAX: PCIN-2016-025), MINECO-FPI (BES-2017-080188), TARGESTORM (SAF2016-75241-R), and the Generalitat de Catalunya (2017 SGR 01536) to E.F., S.P., and L.A. The AGAUR/Generalitat de Catalunya (CERCA Programme 2017-SGR-1442); FEDER funds; Human Brain Project (SGA3 Grant Agreement 945539); MINECO (Deepred); "la Caixa" Foundation (ID 100010434) under the agreement LCF/PR/HR19/52160010); and the $\mathrm{CECH}$ project that is co-financed by the European Union Regional Development Fund within the framework of the ERDF Operational Program of Catalonia 2014-2020 with a grant of $50 \%$ of total eligible cost. L.A. and I.K.V. acknowledge The Netherlands Organisation for Scientific Research (NWO VIDI Grants 723.014.006 and 192.028) for financial support.

\section{REFERENCES}

(1) Krieg, E.; Bastings, M. M. C.; Besenius, P.; Rybtchinski, B. Supramolecular Polymers in Aqueous Media. Chem. Rev. 2016, 116 (4), 2414-2477.

(2) Albertazzi, L.; Martinez-Veracoechea, F. J.; Leenders, C. M. A.; Voets, I. K.; Frenkel, D.; Meijer, E. W. Spatiotemporal Control and Superselectivity in Supramolecular Polymers Using Multivalency. Proc. Natl. Acad. Sci. U. S. A. 2013, 110 (30), 12203-12208.

(3) Matson, J. B.; Stupp, S. I. Drug Release from HydrazoneContaining Peptide Amphiphiles. Chem. Commun. 2011, 47 (28), 7962-7964.

(4) Bakker, M. H.; Lee, C. C.; Meijer, E. W.; Dankers, P. Y. W.; Albertazzi, L. Multicomponent Supramolecular Polymers as a Modular Platform for Intracellular Delivery. ACS Nano 2016, 10 (2), $1845-1852$.

(5) Su, H.; Zhang, W.; Wang, H.; Wang, F.; Cui, H. PaclitaxelPromoted Supramolecular Polymerization of Peptide Conjugates. J. Am. Chem. Soc. 2019, 141 (30), 11997-12004.

(6) Su, H.; Wang, F.; Wang, Y.; Cheetham, A. G.; Cui, H. Macrocyclization of a Class of Camptothecin Analogues into Tubular Supramolecular Polymers. J. Am. Chem. Soc. 2019, 141 (43), 1710717111.

(7) Besenius, P.; Heynens, J. L.; Straathof, R.; Niuwenhuizen, M. M.; Bomans, P.; Terreno, E.; Aime, S.; Strijkers, G.; Nicolay, K.; Meijer, E. W. Paramagnetic self-assembled nanoparticles as supramolecular MRI contrast agents. Contrast Media Mol. Imaging 2012, 7 (3), 356-361.

(8) Orbach, R.; Adler-Abramovich, L.; Zigerson, S.; Mironi-Harpaz, I.; Seliktar, D.; Gazit, E. Self-Assembled Fmoc-Peptides as a Platform for the Formation of Nanostructures and Hydrogels. Biomacromolecules 2009, 10 (9), 2646-2651.
(9) Mata, A.; Geng, Y.; Henrikson, K. J.; Aparicio, C.; Stock, S. R.; Stacher, R. L.; Stupp, S. I. Bone regeneration mediated by biomimetic mineralization of a nanofiber matrix. Biomaterials 2010, 31 (23), 6004-6012.

(10) Choe, S.; Bond, C. W.; Harrington, D. A.; Stupp, S. I.; McVary, K. T.; Podlasek, C. A. Peptide Amphiphile Nanofiber Hydrogel Delivery of Sonic Hedgehog Protein to the Cavernous Nerve to Promote Regeneration and Prevent Erectile Dysfunction. Nanomedicine 2017, 13 (1), 95-101.

(11) Saunders, L.; Ma, P. X. Self-Healing Supramolecular Hydrogels for Tissue Engineering Applications. Macromol. Biosci. 2019, 19, 1800313.

(12) Blum, A. P.; Kammeyer, J. K.; Rush, A. M.; Callmann, C. E.; Hahn, M. E.; Gianneschi, N. C. Stimuli-Responsive Nanomaterials for Biomedical Applications. J. Am. Chem. Soc. 2015, 137 (6), 21402154.

(13) Frisch, H.; Unsleber, J. P.; Lüdeker, D.; Peterlechner, M.; Brunklaus, G.; Waller, M.; Besenius, P. pH-Switchable Ampholytic Supramolecular Copolymers. Angew. Chem., Int. Ed. 2013, 52 (38), 10097-10101.

(14) Gröger, G.; Meyer-Zaika, W.; Böttcher, C.; Gröhn, F.; Ruthard, C.; Schmuck, C. Switchable Supramolecular Polymers from the SelfAssembly of a Small Monomer with Two Orthogonal Binding Interactions. J. Am. Chem. Soc. 2011, 133 (23), 8961-8971.

(15) Moyer, T. J.; Finbloom, J. A.; Chen, F.; Toft, D. J.; Cryns, V. L.; Stupp, S. I. pH and Amphiphilic Structure Direct Supramolecular Behavior in Biofunctional Assemblies. J. Am. Chem. Soc. 2014, 136 (42), 14746-14752.

(16) Ahlers, P.; Frisch, H.; Holm, R.; Spitzer, D.; Barz, M.; Besenius, $\mathrm{P}$. Tuning the $\mathrm{pH}-$ Switch of Supramolecular Polymer Carriers for siRNA to Physiologically Relevant pH. Macromol. Biosci. 2017, 17 (10), 1700111.

(17) Adhikari, B.; Yamada, Y.; Yamauchi, M.; Wakita, K.; Lin, X.; Aratsu, K.; Ohba, T.; Karatsu, T.; Hollamby, M. J.; Shimizu, N.; Takagi, H.; Haruki, R.; Adachi, S.; Yagai, S. Light-induced unfolding and refolding of supramolecular polymer nanofibers. Nat. Commun. 2017, 8, 15254.

(18) Yagai, S.; Yamauchi, M.; Kobayashi, A.; Karatsu, T.; Kitamura, A.; Ohba, T.; Kikkawa, Y. Control over Hierarchy Levels in the SelfAssembly of Stackable Nanotoroids. J. Am. Chem. Soc. 2012, 134 (44), 18205-18208.

(19) Prabhu, D. D.; Aratsu, K.; Kitamoto, Y.; Ouchi, H.; Ohba, T.; Hollamby, M. J.; Shimizu, N.; Takagi, H.; Haruki, R.; Adachi, S.; Yagai, S. Self-folding of supramolecular polymers into bioinspired topology. Sci. Adv. 2018, 4 (9), 8466.

(20) Huang, Z.; Lee, E.; Kim, H.-J.; Lee, M. Aqueous Nanofibers with Switchable Chirality Formed of Self-Assembled DumbbellShaped Rod Amphiphiles. Chem. Commun. 2009, 44, 6819-6821.

(21) Feijter, I.; Besenius, P.; Albertazzi, L.; Meijer, E. W.; Palmans, A. R. A.; Voets, I. K. Mechanistic control over morphology: selfassembly of a discotic amphiphile in water. Soft Matter 2013, 9 (42), 10025-10030.

(22) Alemán García, M. Á.; Magdalena Estirado, E.; Milroy, L.-G.; Brunsveld, L. Dual-Input Regulation and Positional Control in Hybrid Oligonucleotide/Discotic Supramolecular Wires. Angew. Chem., Int. Ed. 2018, 57 (18), 4976-4980.

(23) Kumar, M.; Brocorens, P.; Tonnelé, C.; Beljonne, D.; Surin, M.; George, S. J. A Dynamic Supramolecular Polymer with StimuliResponsive Handedness for in Situ Probing of Enzymatic ATP Hydrolysis. Nat. Commun. 2014, 5, 5793.

(24) Mishra, A.; Korlepara, D. B.; Balasubramanian, S.; George, S. J. Bioinspired, ATP-driven co-operative supramolecular polymerization and its pathway dependence. Chem. Commun. 2020, 56, 1505-1508.

(25) Albertazzi, L.; van der Veeken, N.; Baker, M. B.; Palmans, A. R. A.; Meijer, E. W. Supramolecular Copolymers with StimuliResponsive Sequence Control. Chem. Commun. 2015, 51 (90), 16166-16168. 
(26) Molla, M. R.; Prasad, P.; Thayumanavan, S. Protein-Induced Supramolecular Disassembly of Amphiphilic Polypeptide Nanoassemblies. J. Am. Chem. Soc. 2015, 137 (23), 7286-7289.

(27) van Dun, S.; Ottmann, C.; Milroy, L.; Brunsveld, L. Supramolecular Chemistry Targeting Proteins. J. Am. Chem. Soc. 2017, 139 (40), 13960-13968.

(28) Guo, J.; Zhuang, J.; Wang, F.; Raghupathi, K. R.; Thayumanavan, S. Protein AND Enzyme Gated Supramolecular Disassembly. J. Am. Chem. Soc. 2014, 136 (6), 2220-2223.

(29) Erbas-Cakmak, S.; Kolemen, S.; Sedgwick, A. C.; Gunnlaugsson, T.; James, T. D.; Yoon, J.; Akkaya, E. U. Molecular logic gates: the past, present and future. Chem. Soc. Rev. 2018, 47, 2228.

(30) Gao, J.; Wu, P.; Fernandez, A.; Zhuang, J.; Thayumanavan, S. Cellular AND Gates: Synergistic Recognition to Boost Selective Uptake of Polymeric Nanoassemblies. Angew. Chem., Int. Ed. 2020, 59, 1-6.

(31) Spitzer, D.; Rodrigues, L. L.; Straßburger, D.; Mezger, M.; Besenius, P. Tuneable Transient Thermogels Mediated by a $\mathrm{pH}$ - and Redox-Regulated Supramolecular Polymerization. Angew. Chem., Int. Ed. 2017, 56 (48), 15461-15465.

(32) Goskulwad, S.; La, D. D.; Kobaisi, M. A.; Bhosale, S. V.; Bansal, V.; Vinu, A.; Ariga, K.; Bhosale, S. V. Dynamic multistimuli-responsive reversible chiral transformation in supramolecular helices. Sci. Rep. 2018, 8 (1), 1-11.

(33) Liu, X.; Hu, D.; Jiang, Z.; Zhuang, J.; Xu, Y.; Guo, X.; Thayumanavan, S. Multi-Stimuli-Responsive Amphiphilic Assemblies through Simple Postpolymerization Modifications. Macromolecules 2016, 49 (17), 6186-6192.

(34) Chen, J.; Zhang, S.; Sun, F.; Li, N.; Cui, K.; He, J.; Niu, D.; Li, Y. Multi-stimuli responsive supramolecular polymers and their electrospun nanofibers. Polym. Chem. 2016, 7 (17), 2947-2954.

(35) Cantekin, S.; Nakano, Y.; Everts, J. C.; van der Schoot, P.; Meijer, E. W.; Palmans, A. R. A. A Stereoselectively Deuterated Supramolecular Motif to Probe the Role of Solvent during SelfAssembly Processes. Chem. Commun. 2012, 48 (32), 3803-3805.

(36) Pianowski, Z. L. Recent Implementations of Molecular Photoswitches into Smart Materials and Biological Systems. Chem. Eur. J. 2019, 25 (20), 5128-5144.

(37) Szymański, W.; Beierle, J. M.; Kistemaker, H. A. V.; Velema, W. A.; Feringa, B. L. Reversible Photocontrol of Biological Systems by the Incorporation of Molecular Photoswitches. Chem. Rev. 2013, 113 (8), 6114-6178.

(38) Ishikawa, M.; Ohzono, T.; Yamaguchi, T.; Norikane, Y. PhotoEnhanced Aqueous Solubilization of an Azo-Compound. Sci. Rep. 2017, 7 (1), 1-6.

(39) Vancoillie, G.; Frank, D.; Hoogenboom, R. Thermoresponsive Poly(oligo Ethylene Glycol Acrylates). Prog. Polym. Sci. 2014, 39 (6), 1074-1095.

(40) Lüsse, S.; Arnold, K. The Interaction of Poly(ethylene Glycol) with Water Studied by $1 \mathrm{H}$ and $2 \mathrm{H}$ NMR Relaxation Time Measurements. Macromolecules 1996, 29 (12), 4251-4257.

(41) Chandler, D. Interfaces and the Driving Force of Hydrophobic Assembly. Nature 2005, 437 (7059), 640-647.

(42) Smith, G. D.; Bedrov, D. Roles of Enthalpy, Entropy, and Hydrogen Bonding in the Lower Critical Solution Temperature Behavior of Poly(ethylene oxide)/Water Solutions. J. Phys. Chem. B 2003, 107 (14), 3095-3097.

(43) Besenius, P.; Goedegebure, Y.; Driesse, M.; Koay, M.; Bomans, P.; Palmans, A. R. A.; Dankers, P. Y. W.; Meijer, E. W. Peptide functionalised discotic amphiphiles and their self-assembly into supramolecular nanofibres. Soft Matter 2011, 7 (18), 7980-7983.

(44) Volgraf, M.; Gorostiza, P.; Szobota, S.; Helix, M. R.; Isacoff, E. Y.; Trauner, D. Reversibly Caged Glutamate: A Photochromic Agonist of Ionotropic Glutamate Receptors. J. Am. Chem. Soc. 2007, $129,260-261$.

(45) Riefolo, F.; Matera, C.; Garrido-Charles, A.; Gomila, A. M. J.; Sortino, R.; Agnetta, L.; Claro, E.; Masgrau, R.; Holzgrabe, U.; Batlle, M.; Decker, M.; Guasch, E.; Gorostiza, P. Optical Control of Cardiac
Function with a Photoswitchable Muscarinic Agonist. J. Am. Chem. Soc. 2019, 141, 7628-7636.

(46) Bandara, H. M. D.; Burdette, S. C. Photoisomerization in Different Classes of Azobenzene. Chem. Soc. Rev. 2012, 41 (5), 18091825.

(47) Titov, E.; Granucci, G.; Götze, J. P.; Persico, M.; Saalfrank, P. Dynamics of Azobenzene Dimer Photoisomerization: Electronic and Steric Effects. J. Phys. Chem. Lett. 2016, 7 (18), 3591-3596.

(48) Cocchi, C.; Draxl, C. Understanding the Effects of Packing and Chemical Terminations on the Optical Excitations of AzobenzeneFunctionalized Self-Assembled Monolayers. J. Phys.: Condens. Matter 2017, 29 (39), 394005.

(49) Galanti, A.; Diez-Cabanes, V.; Santoro, J.; Valasek, M.; Minoia, A.; Mayor, M.; Cornil, J.; Samorì, P. Electronic Decoupling in C3Symmetrical Light-Responsive Tris(Azobenzene) Scaffolds: SelfAssembly and Multiphotochromism. J. Am. Chem. Soc. 2018, 140 (47), 16062-16070.

(50) Tong, X.; Wang, G.; Soldera, A.; Zhao, Y. How Can Azobenzene Block Copolymer Vesicles Be Dissociated and Reformed by Light? J. Phys. Chem. B 2005, 109 (43), 20281-20287.

(51) Liu, M.; Zhang, L.; Wang, T. Supramolecular Chirality in SelfAssembled Systems. Chem. Rev. 2015, 115 (15), 7304-7397.

(52) Casellas, N. M.; Pujals, S.; Bochicchio, D.; Pavan, G. M.; Torres, T.; Albertazzi, L.; García-Iglesias, M. From isodesmic to highly cooperative: reverting the supramolecular polymerization mechanism in water by fine monomer design. Chem. Commun. 2018, 54 (33), 4112-4115.

(53) Hamley, I. W.; Cheng, G.; Castelletto, V. A. Thermoresponsive Hydrogel Based on Telechelic PEG End-Capped with Hydrophobic Dipeptides. Macromol. Biosci. 2011, 11 (8), 1068-1078.

(54) Fuller, J. M.; Raghupathi, K. R.; Ramireddy, R. R.; Subrahmanyam, A. V.; Yesilyurt, V.; Thayumanavan, S. Temperature-Sensitive Transitions below LCST in Amphiphilic Dendritic Assemblies: Host-Guest Implications. J. Am. Chem. Soc. 2013, 135 (24), 8947-8954.

(55) Engel, S.; Spitzer, D.; Rodrigues, L. L.; Fritz, E.; Straßburger, D.; Schönhoff, M.; Ravoo, B. J.; Besenius, P. Kinetic control in the temperature-dependent sequential growth of surface-confined supramolecular copolymers. Faraday Discuss. 2017, 204 (0), 53-67.

(56) Frisch, H.; Fritz, E.; Stricker, F.; Schmüser, L.; Spitzer, D.; Weidner, T.; Ravoo, B. J.; Besenius, P. Kinetically Controlled Sequential Growth of Surface-Grafted Chiral Supramolecular Copolymers. Angew. Chem., Int. Ed. 2016, 55 (25), 7242-7246.

(57) Besenius, P.; Portale, G.; Bomans, P.; Janssen, H. M.; Palmans, A. R. A.; Meijer, E. W. Controlling the Growth and Shape of Chiral Supramolecular Polymers in Water. Proc. Natl. Acad. Sci. U. S. A. 2010, 107 (42), 17888-17893. 